Article

\title{
The Inhibitory Effect of Botulinum Toxin Type A on Rat Pyloric Smooth Muscle Contractile Response to Substance P In Vitro
}

\author{
Yu-Feng Shao ${ }^{1, \dagger}$, Jun-Fan Xie ${ }^{1, \dagger}$, Yin-Xiang Ren ${ }^{1}$, Can Wang ${ }^{1}$, Xiang-Pan Kong ${ }^{1,2}$, \\ Xiao-Jian Zong ${ }^{3}$, Lin-Lan Fan ${ }^{4}$ and Yi-Ping Hou ${ }^{1, *}$
}

1 Department of Neuroscience, Anatomy, Histology and Embryology, Key Laboratory of Preclinical Study for New Drugs of Gansu Province, School of Basic Medical Sciences, Lanzhou University, 199 Donggang Xi Road, Lanzhou 730000, China; E-Mails: shaoyf@1zu.edu.cn (Y.-F.S.); xiejfan@163.com (J.-F.X.); renyx@1zu.edu.cn (Y.-X.R.); wangc2012@1zu.cn (C.W.); kongxp530@163.com (X.-P.K.)

2 Department of Human Anatomy, School of Medicine, Hunan Normal University, 371 Tongzipo Road, Changsha 410013, China

3 Department of Functional Examination, the 2nd Hospital of Gansu Province, Lanzhou 730000, China; E-Mail: zxj0547@163.com

4 Experimental Center of Medicine, School of Basic Medical Sciences, Lanzhou University, 199 Donggang Xi Road, Lanzhou 730000, China; E-Mail: fanll@1zu.edu.cn

$\dagger$ These authors contributed equally to this work.

* Author to whom correspondence should be addressed; E-Mail: houyiping@1zu.edu.cn; Tel./Fax: +86-931-8915886.

Academic Editor: Bahman Jabbari

Received: 28 July 2015 / Accepted: 8 October 2015 / Published: 15 October 2015

\begin{abstract}
A decrease in pyloric myoelectrical activity and pyloric substance $\mathrm{P}$ (SP) content following intrasphincteric injection of botulinum toxin type A (BTX-A) in free move rats have been demonstrated in our previous studies. The aim of the present study was to investigate the inhibitory effect of BTX-A on rat pyloric muscle contractile response to SP in vitro and the distributions of SP and neurokinin 1 receptor (NK1R) immunoreactive (IR) cells and fibers within pylorus. After treatment with atropine, BTX-A (10 U/mL), similar to [D-Arg ${ }^{1}$, D-Phe ${ }^{5}$, D-Trp ${ }^{7,9}$, Leu $^{11}$ ]-SP (APTL-SP, $1 \mu \mathrm{mol} / \mathrm{L}$ ) which is an NK1R antagonist, decreased electric field stimulation (EFS)-induced contractile tension and frequency, whereas, subsequent administration of APTL-SP did not act on contractility. Incubation with
\end{abstract}


BTX-A at 4 and $10 \mathrm{U} / \mathrm{mL}$ for $4 \mathrm{~h}$ respectively decreased SP $(1 \mu \mathrm{mol} / \mathrm{L})$-induced contractions by $26.64 \% \pm 5.12 \%$ and $74.92 \% \pm 3.62 \%$. SP-IR fibers and NK1R-IR cells both located within pylorus including mucosa and circular muscle layer. However, fewer SP-fibers were observed in pylorus treated with BTX-A $(10 \mathrm{U} / \mathrm{mL})$. In conclusion, BTX-A inhibits SP release from enteric terminals in pylorus and EFS-induced contractile responses when muscarinic cholinergic receptors are blocked by atropine. In addition, BTX-A concentrationand time-dependently directly inhibits SP-induced pyloric smooth muscle contractility.

Keywords: botulinum toxin type A; substance P; electric field stimulation; neurokinin 1 receptor; antagonist of neurokinin 1 receptor; pyloric smooth muscle contractility; rat

\section{Introduction}

Botulinum toxin (BTX) is produced from the bacterium clostridium botulinum. Seven distinct serotypes have been identified and designated as types A, B, C, D, E, F and G [1-3]. It is well investigated that the major target of BTX is the cholinergic nerve ending of neuromuscular junctions in skeletal muscles, where the inhibition of acetylcholine (ACh) release results in neuromuscular blockade and paralysis $[4,5]$. Currently, BTX-A has been successfully used in the treatment of voluntary muscle contraction disorders such as strabismus, dystonia, and tremors [4,6-9].

However, in smooth muscles, an injection of BTX-A into pylorus in patients with gastroparesis might relax the pylorus and facilitate gastric emptying. Several small open-label studies have also shown this in diabetic gastroparesis [10,11] and in idiopathic gastroparesis [12]. In gastrointestinal smooth muscle, BTX-A appears to reduce cholinergic transmission by inhibiting ACh release, as shown in vitro [13,14] and in vivo [15]. In addition, our recent studies have demonstrated that BTX-A intrasphincteric injection through guide cannula in free move rats dose-dependently caused an inhibition of slow wave in amplitude but not in frequency, a diminishment of spike activity in amplitude and spike burst of pyloric myoelectrical activity, and a reduction of substance P (SP) content within pylorus [16]. These data suggest that BTX-A inhibit not only the ACh release but also SP release from the autonomic and enteric nervous terminals in pylorus.

SP, a major excitatory non-cholinergic neurotransmitter, depolarizes the membrane potential and thus induces contraction in gastrointestinal smooth muscle [17,18]. It is an undecapeptide belonging to the tachykinin family and can induce strong contractions in pylorus via neurokinin 1 receptor (NK1R), the preferred receptor for SP [19]. However, no experimental evidence that BTX-A inhibits the pyloric contractile response induced by SP released from nervous terminals or SP dosed has been documented so far.

The present studies were designed to provide information regarding the inhibitory target of BTX-A for SP. Primarily, to investigate the inhibitory effect of BTX-A on contractile tension and frequency of pyloric muscle strips after the effect of ACh being abolished by atropine, an antagonist of cholinergic muscarinic receptor, and compare with the inhibitory effect of NK1R antagonist in same condition. Secondly, measure the pyloric smooth muscle contractile response to SP under a range concentration of 
BTX-A incubation. Finally, examine the distributions of SP and NK1R immunoreacive cells and fibers in pylorus treated without and with BTX-A by immunofluorescence.

\section{Results}

\subsection{Inhibitory Effect of BTX-A on Contractile Response to SP Release from Pylorus}

Electric field stimulation (EFS) was used to induce neurotransmitter release from pylorus and increase pyloric smooth muscle contractility. In the first group, as shown in Figure 1, EFS significantly induced an increase in pyloric contractile tension (from $1.458 \pm 0.029$ to $2.240 \pm 0.070 \mathrm{~g}, p<0.001$; Figure $1 \mathrm{~A}, \mathrm{~B}$ ) and frequency (from $0.928 \pm 0.038$ to $2.980 \pm 0.078 \mathrm{~Hz}, p<0.001$; Figure 1A,C). The addition of atropine $(1 \mu \mathrm{mol} / \mathrm{L})$ after $30 \mathrm{~min}$ partially decreased contractile tension (from $2.240 \pm 0.070$ to $1.944 \pm 0.090 \mathrm{~g}, p<0.005$ ), but did not affect its frequency (Figure 1A-C). Subsequently, [D-Arg1, D-Phe5, D-Trp7,9, Leu11]-SP (APTL-SP) was added and it further decreased contractile tension (from $1.944 \pm 0.090$ to $1.376 \pm 0.036 \mathrm{~g}, p<0.001$ ) and frequency (from $3.028 \pm 0.054$ to $1.820 \pm 0.034 \mathrm{~Hz}, p<0.001$ ) (Figure 1A-C).

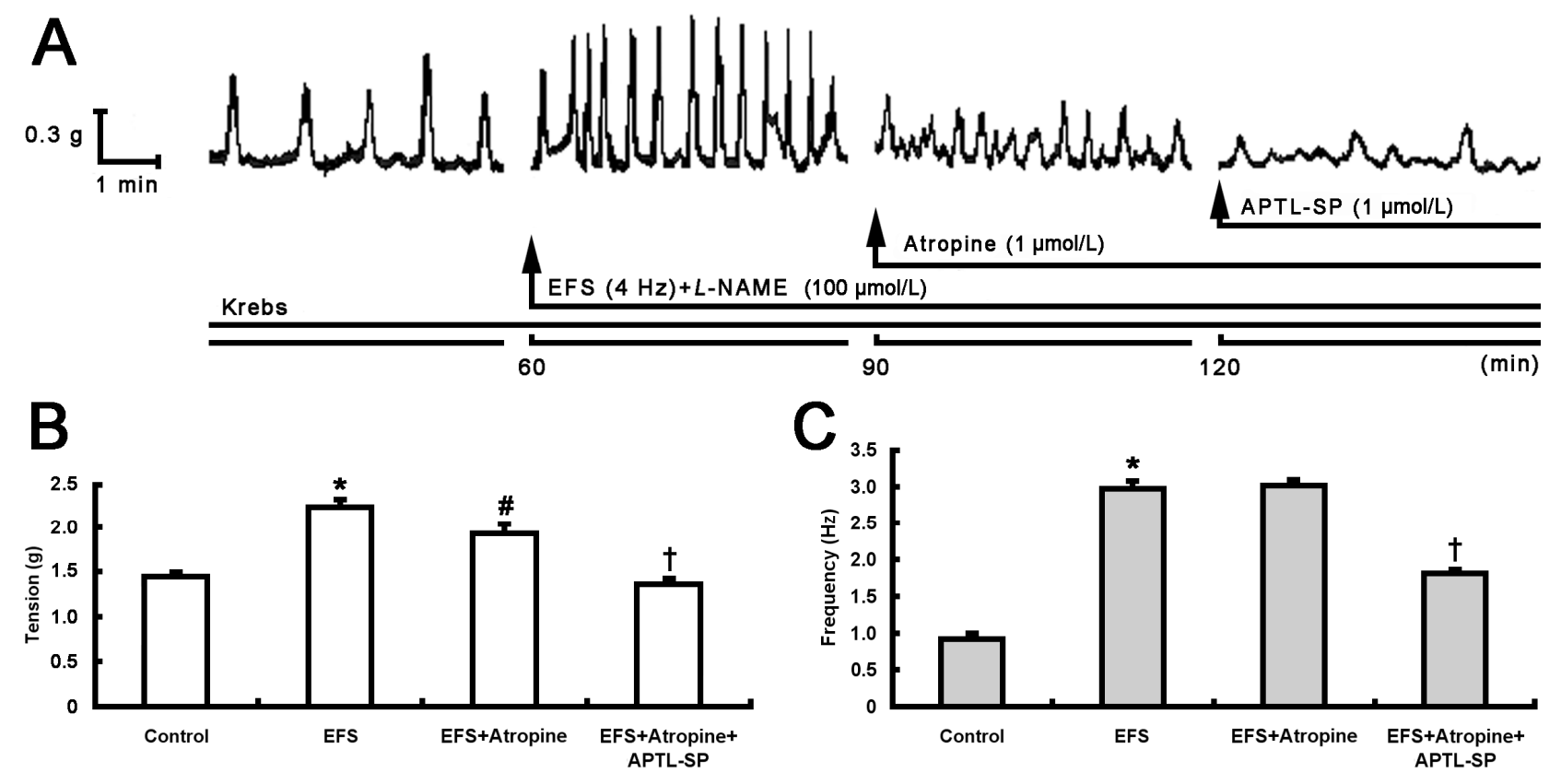

Figure 1. Effect of APTL-SP on EFS-induced pyloric contractile responses following atropine action. (A) Representative 2-h contractile recording curves show that EFS (4 Hz) enhanced spontaneous contraction of pyloric smooth muscle strip incubated with Krebs solution containing N $\omega$-nitro-L-arginine methyl ester (L-NAME, $100 \mu \mathrm{mol} / \mathrm{L}$ ), then atropine $(1 \mu \mathrm{mol} / \mathrm{L})$ addition at $90 \mathrm{~min}$ partially decreased the EFS-induced contractile responses and subsequent addition of APTL-SP $(1 \mu \mathrm{mol} / \mathrm{L})$ at $120 \mathrm{~min}$ further decreased the contractility. The statistical significance in contractile tension (B) and frequency (C) of pyloric strips performed respectively with Krebs solution as control, EFS, EFS + Atropine and EFS + Atropine + APTL-SP are shown. Data are expressed as means $\pm \mathrm{SEM}, n=8$, analyzed by one-way ANOVA followed by Fisher's PLSD test. * $p<0.001$, EFS $v s$. control; ${ }^{*} p<0.005$, $\mathrm{EFS}+$ Atropine $v s . \mathrm{EFS} ;{ }^{\dagger} p<0.001, \mathrm{EFS}+$ Atropine + APTL-SP $v s . \mathrm{EFS}+$ Atropine. 
In the second group (Figure 2), BTX-A (10 U/mL) instead of APTL-SP further decreased contractile tension and frequency (Figure 2A-C) following atropine. The inhibitory effect of BTX-A on pyloric contractility was similar to that of APTL-SP. Noticeably, subsequent addition of APTL-SP following BTX-A action had no effect on pyloric contractility in tension and frequency (Figure $2 \mathrm{~A}-\mathrm{C}$ ).

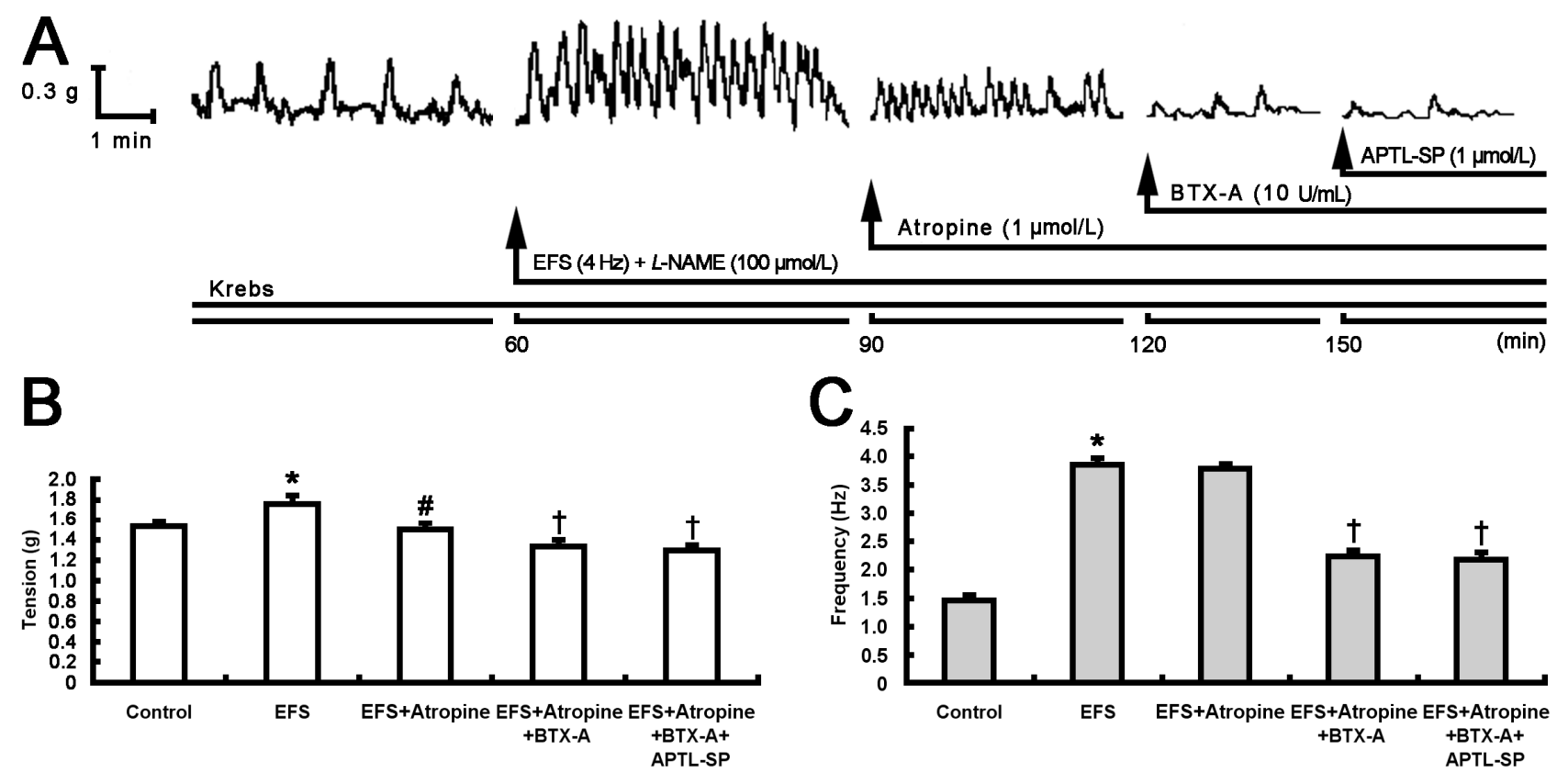

Figure 2. Effect of BTX-A on EFS-induced pyloric contractile responses following atropine action. (A) Representative 2.5-h contractile recording curves show that EFS (4 Hz) enhanced spontaneous contraction of pyloric smooth muscle strip incubated with Krebs solution containing L-NAME $(100 \mu \mathrm{mol} / \mathrm{L})$, then atropine $(1 \mu \mathrm{mol} / \mathrm{L})$ addition at $90 \mathrm{~min}$ partially decreased the EFS-induced contractile responses, subsequent addition of BTX-A $(10 \mathrm{U} / \mathrm{mL})$ at $120 \mathrm{~min}$ further decreased the contractility and finally, APTL-SP $(1 \mu \mathrm{mol} / \mathrm{L})$ addition at $150 \mathrm{~min}$ did not act on. The statistical significance in contractile tension (B) and frequency (C) of pyloric strips performed respectively with Krebs solution as control, EFS, EFS + Atropine, EFS + Atropine + BTX-A and EFS + Atropine + BTX-A + APTL-SP are shown. Data are expressed as means $\pm \mathrm{SEM}, n=8$, analyzed by one-way ANOVA followed by Fisher's PLSD test. * $p<0.001$, EFS vs. control; ${ }^{*} p<0.001$, EFS + Atropine vs. EFS; ${ }^{\dagger} p<0.001, \mathrm{EFS}+$ Atropine + BTX-A or EFS + Atropine + BTX-A + APTL-SP $v s$. EFS + Atropine.

\subsection{Inhibitory Effect of BTX-A on SP-induced Contractile Response}

The inhibitory effect of different concentrations of BTX-A on SP-induced pyloric muscle contractility was further studied. As shown in Figure 3, SP $(1 \mu \mathrm{mol} / \mathrm{L})$ induced an increase in pyloric contractility (Figure 3A), whereas pyloric muscle strips incubated with 4 and $10 \mathrm{U} / \mathrm{mL}$ BTX-A concentration- and time-dependently decreased the contractile response to SP through the experimental period (Figure 3A,B), and respectively decreased SP-induced contractions by $26.64 \% \pm 5.12 \%(p<0.01)$ and $74.92 \% \pm 3.62 \%(p<0.001)$ at the end of $4 \mathrm{~h}$ (Figure $3 \mathrm{~B})$. 

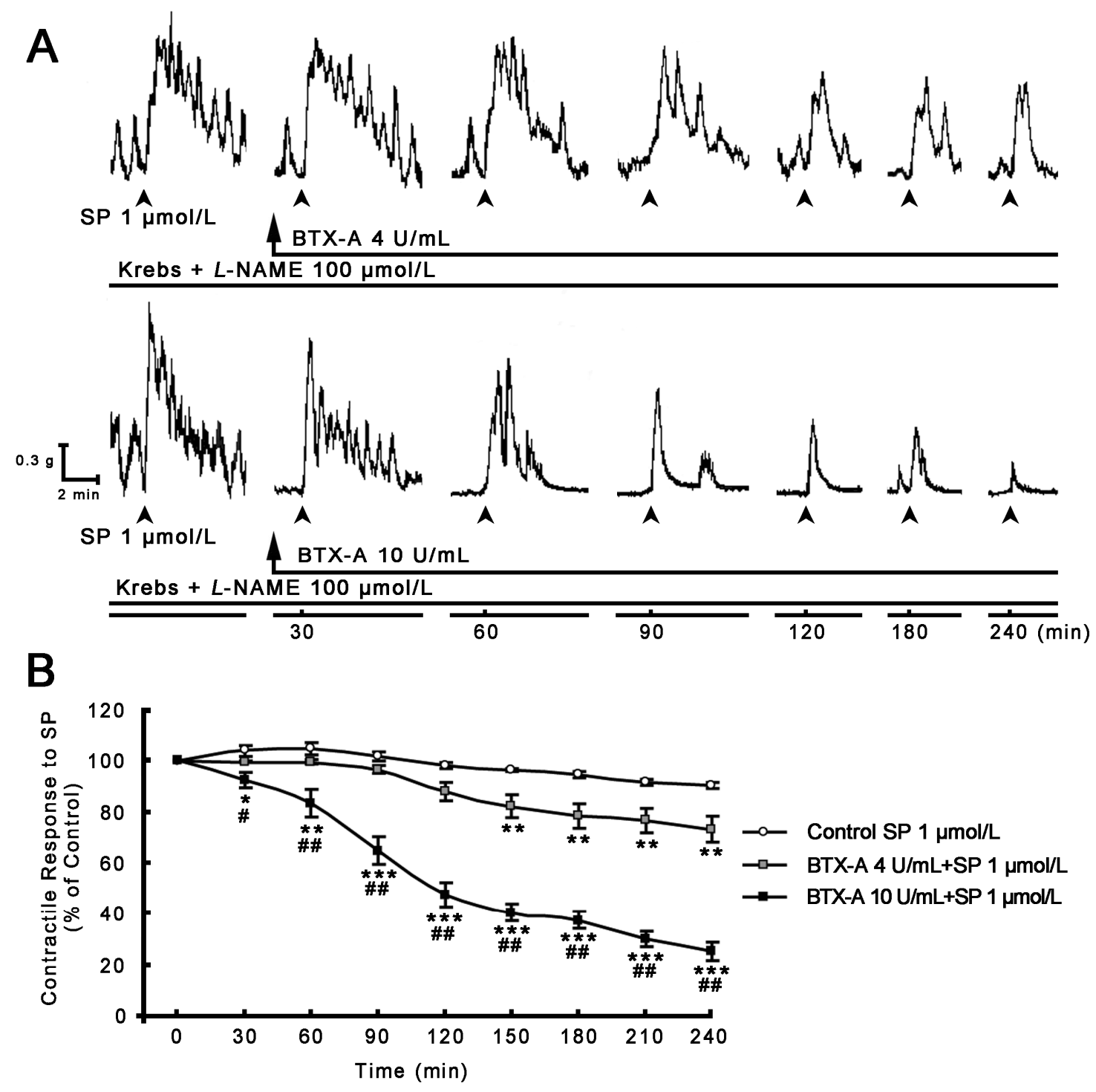

Figure 3. Effect of BTX-A on SP-induced pyloric contractile responses. (A) Representative 4-h contractile recording curves show that SP induced an increase in pyloric spontaneous contractions, and that incubation with BTX-A from 4 (upper panel) to $10 \mathrm{U} / \mathrm{mL}$ (lower panel) concentration- and time-dependently decreased SP-induced pyloric contractile responses (SP was added at interval $30 \mathrm{~min}$ and shown by head of arrow); (B) BTX-A statistically inhibited SP-induced contractile responses with concentration- and time-dependent manner. Data are expressed as means \pm SEM, $n=8$ in each group, analyzed by one-way ANOVA followed by Fisher's PLSD test. * $p<0.05$, ** $p<0.01$, *** $p<0.001$, vs. control; ${ }^{*} p<0.01,{ }^{\#} p<0.001$, BTX-A $10 \mathrm{U} / \mathrm{mL} v s .4 \mathrm{U} / \mathrm{mL}$.

\subsection{Distribution of SP-and NK1R-Immunoreactive Expressions in Pylorus without or with BTX-A Treatment}

In the pylorus without BTX-A treatment, beaded SP immunereactive (IR) fibers located in lamina propria and were preference near to epithelium of mucosa (Figure 4C). NK1R-IR cells were mainly found in lamina propria, and scattered in epithelium of mucosa (Figure 4B). In pyloric sphincter, which composed by thickening circular muscle, SP-IR fibers (Figure 4E) and NK1R-IR cells (Figure 4D) were 
diffusely expressed in these areas. In the pylorus treated with BTX-A, the expression of NK1R-IR cells in mucous (Figure 4F) and pyloric sphincter (Figure 4H) was similar to the pylorus treated without BTX-A. However, fewer SP-IR fibers were observed in mucous (Figure 4G) and pyloric sphincter (Figure 4I) compared to control. The fact that both NK1R-IR and SP-IR expressed in the same area indicates that SP through NK1R acts on pyloric smooth muscle. BTX-A inhibited SP release form enteric terminals in pylorus.
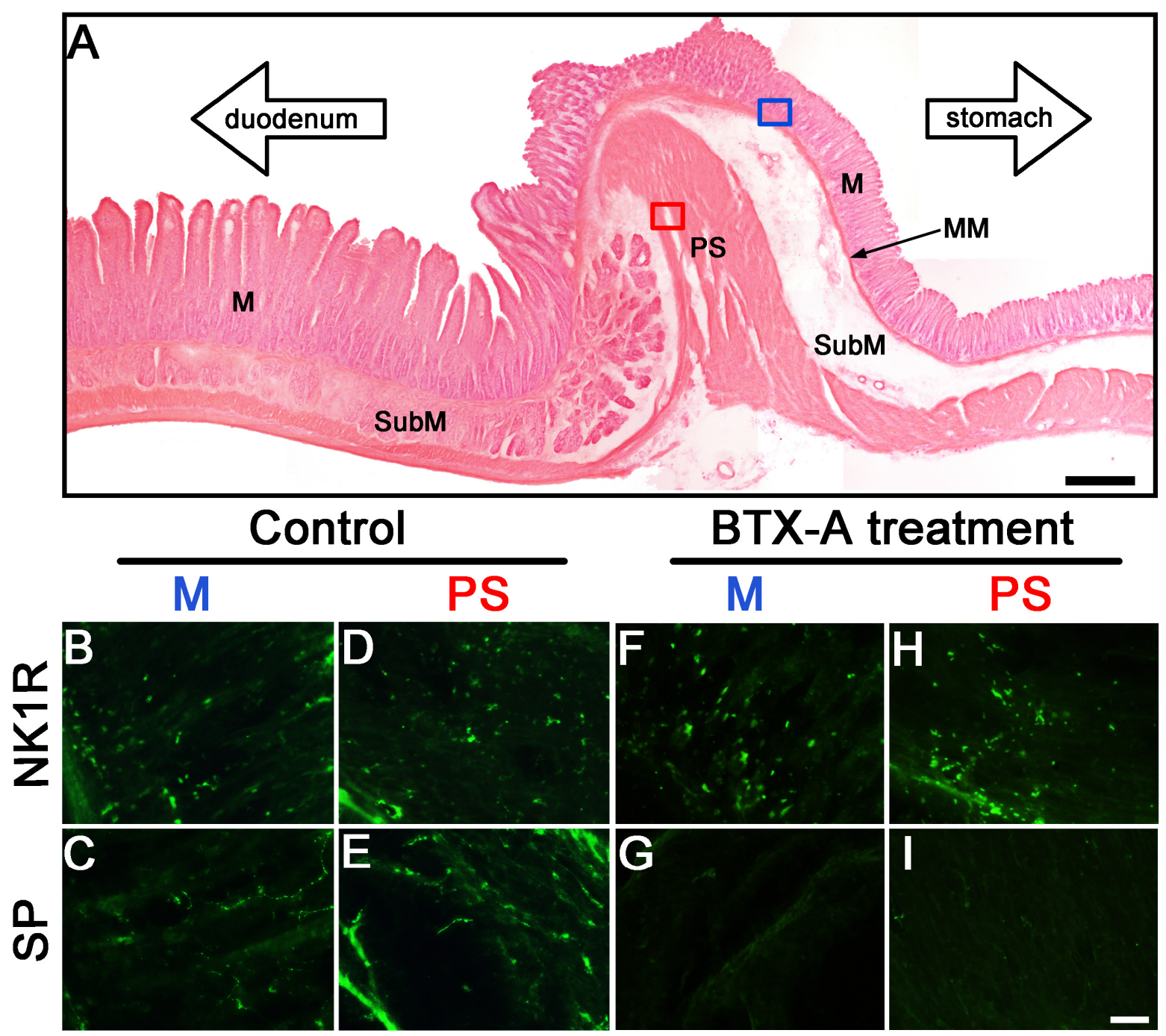

Figure 4. Distributions of SP- and NK1R-IR fibers and cells within pylorus treated without or with BTX-A. (A) Photograph shows the structure of pyloric longitudinal tissue stained with HE: M, mucous; MM, muscularis mucosae; PS, pyloric sphincter; SubM, submucos. Bar $=500 \mu \mathrm{m}$. (B-I) Photographs show the distributions and morphological characteristics of NK1R- and SP-IR cells and fibers in mucous (blue box in $\mathbf{A}$ ) and circular muscles (red box in A) without (control, B-E) or with BTX-A treatment (F-I). NK1R-IR expressed cells mainly in lamina propria of mucous and scattered in epithelium of mucous $(\mathbf{B})$ and diffusely expressed in circular muscle (D). Varicosities of SP-IR fibers vertically projected from lamina propria to epithelium of mucosa $(\mathbf{C})$ and scattered in circular muscle $(\mathbf{E})$. After $10 \mathrm{U} / \mathrm{mL}$ BTX-A treatment, a dense expression of NK1R-IR cells was found in M (F) and PS $(\mathbf{H})$. However, the SP-IR fibers were few in M $(\mathbf{G})$ and PS $(\mathbf{I})$. Bar $=25 \mu \mathrm{m}$. 


\section{Discussion}

Intrasphincteric injection of BTX-A has been recently proposed as an alternative to treat pyloric dysfunction or pylorospasm [14] and demonstrated that it induces a decrease in pyloric myoelectrical activity and pyloric SP content in free move rats [16]. Our current results documented that atropine and subsequent APTL-SP incrementally decreased EFS-induced contractile responses in rat pyloric smooth muscle strips (Figure 1). When BTX-A instead of APTL-SP was added following atropine, its inhibitory effect on EFS-induced contractile responses was similar to APTL-SP, and then APTL-SP addition did not influence contractile responses to EFS again (Figure 2). EFS is a perfect method to induce neurotransmitters release including cholinergic and non-cholinergic neurotransmitters in gastrointestine [14,20]. The evidence of APTL-SP, an NK1R antagonist, further inhibited EFS-induced contractility after atropine blocking muscarinic cholinergic receptors suggests that EFS does not induce only ACh, but also SP release from pylorus. By comparison, the evidence that APTL-SP administration does not act on contractile responses to EFS following inhibition of BTX-A indicates that BTX-A prevents presynaptic vesicles containing SP from fusion with plasma membrane and leads to SP inaction on NK1R within pylorus. SP, similar to ACh can induce strong contractions in pylorus [19] and enhance spike discharges in gastric myoelectrical activity [21]. Several experimental studies have also demonstrated that BTX-A inhibits SP release from pyloric sphincter in rats [16], nasal mucosa of rat allergic rhinitis [22], trigeminal nerve terminals of the rabbit iris sphincter [23], cultured embryonic dorsal root ganglion neurons [24] and isolated bladders in rat bladder models of both acute injury and chronic inflammation [25].

Our results have further shown that BTX-A concentration- and time-dependently inhibited SP-induced contractile tension and frequency in pylorus (Figure 3). When incubating of the muscle strips to BTX-A for a prolonged period $(4 \mathrm{~h})$, the inhibitory effects of BTX-A on SP-induced contractions were not immediate; the onset of inhibitory effect was gradual and slowly progressive. This time-dependent effect may be related to either the mechanism of action of BTX-A or diffusion of the toxin into the tissue. When incubation of the muscle strips at four and $10 \mathrm{U} / \mathrm{mL}$ BTX-A respectively decreased the contractile response to SP by $26.64 \% \pm 5.12 \%$ and $74.92 \% \pm 3.62 \%$ after $4 \mathrm{~h}$ suggesting its inhibitory effects on SP-induced pyloric contractility were also concentration-dependent. The inhibitory characteristics of concentration- and time-dependent effects of BTX-A have also been documented on pyloric myoelectrical activity in vivo [16], pyloric and antral contractility in vitro [14], common bile duct (CBD) pressure [15,26] and lipogenesis [27].

Besides, our study has examined that the distribution of neuronal SP- and NK1R-containing cells and nerve fibers in rat pylorus for understanding the targets of BTX-A action. SP-IR fibers and NK1R-IR cells located in mucosa and circular muscle layers of pylorus (Figure 4). However, fewer SP-IR fibers in the pylorus treated with BTX-A were observed in mucous (Figure 4G) and pyloric sphincter (Figure 4I) compared to control. These results indicate that SP through NK1R innervates inner edge of the circular muscle and layer adjacent to the mucosa of pylorus, which plays an important role in the regulation of gastric emptying [28-30].

Based on the current and previous studies, we proposed the mechanism of inhibitory effects of BTX-A on smooth muscle (Figure 5). Classically, in striated muscle, BTX-A inhibits ACh release from cholinergic nerves [4]. A four-step mechanism consisting of binding, internalization, translocation and cleaving soluble NSF accessory protein receptor (SNARE) protein is currently the accepted view to 
explain BTX-A intoxication [31-34]. BTX-A consists of a heavy chain ( $\mathrm{HC}, \sim 100 \mathrm{kDa})$ and a light chain (LC, $\sim 50 \mathrm{kDa}$ ) linked by a single disulfide bound and non-covalent forces [35,36]. HC can bind to the synaptic membrane and then its entire molecule is internalized into the synaptic terminal by receptor-mediated endocytosis. LC selectively cleaves the synaptosomal-associated protein of $25 \mathrm{kDa}$ (SNAP-25) [37], leading to the ACh-containing vesicles can no longer fuse with the plasma membrane, and exocytosis of ACh is inhibited [38-40]. In gastrointestinal smooth muscle, SP coexists with ACh and enkephalin [41-45], thus, BTX-A may inhibit ACh release accompanied with the inhibition of SP release (Figure 5). SP, in this study, may acts primarily on NK1R to contract pyloric smooth muscles, because the contractions to EFS were further inhibited by APTL-SP, an NK1R antagonist, when atropine blocked muscarinic cholinergic receptors. BTX-A directly inhibits exogenous SP-induced smooth muscle contractility as evidenced by the time-dependently abolished contractile response to SP administration. The effect of BTX-A might directly involve in acetylcholine related contractility which results in a low response to SP administration, since SP as a co-neurotransmitter that appears to be important for the maintenance of muscular responsiveness to the principal excitatory neurotransmitter, ACh [46]. The exact cellular mechanism of BTX-A inhibiting SP-induced contractions was not detailed in the current study. Noticeably, SNAP-25, the substrate for BTX-A, has also been found in gastrointestinal smooth muscle and inhibits outward potassium currents under physiologic condition. When the inhibition of SNAP-25 removed by BTX-A, it leads the membrane hyperpolarized and thereby muscle tone decreased $[47,48]$. This suggests that besides the classical presynaptic neuron sites to reduce neurotransmitter release, there is also another site for BTX-A in regulating muscle contractility.

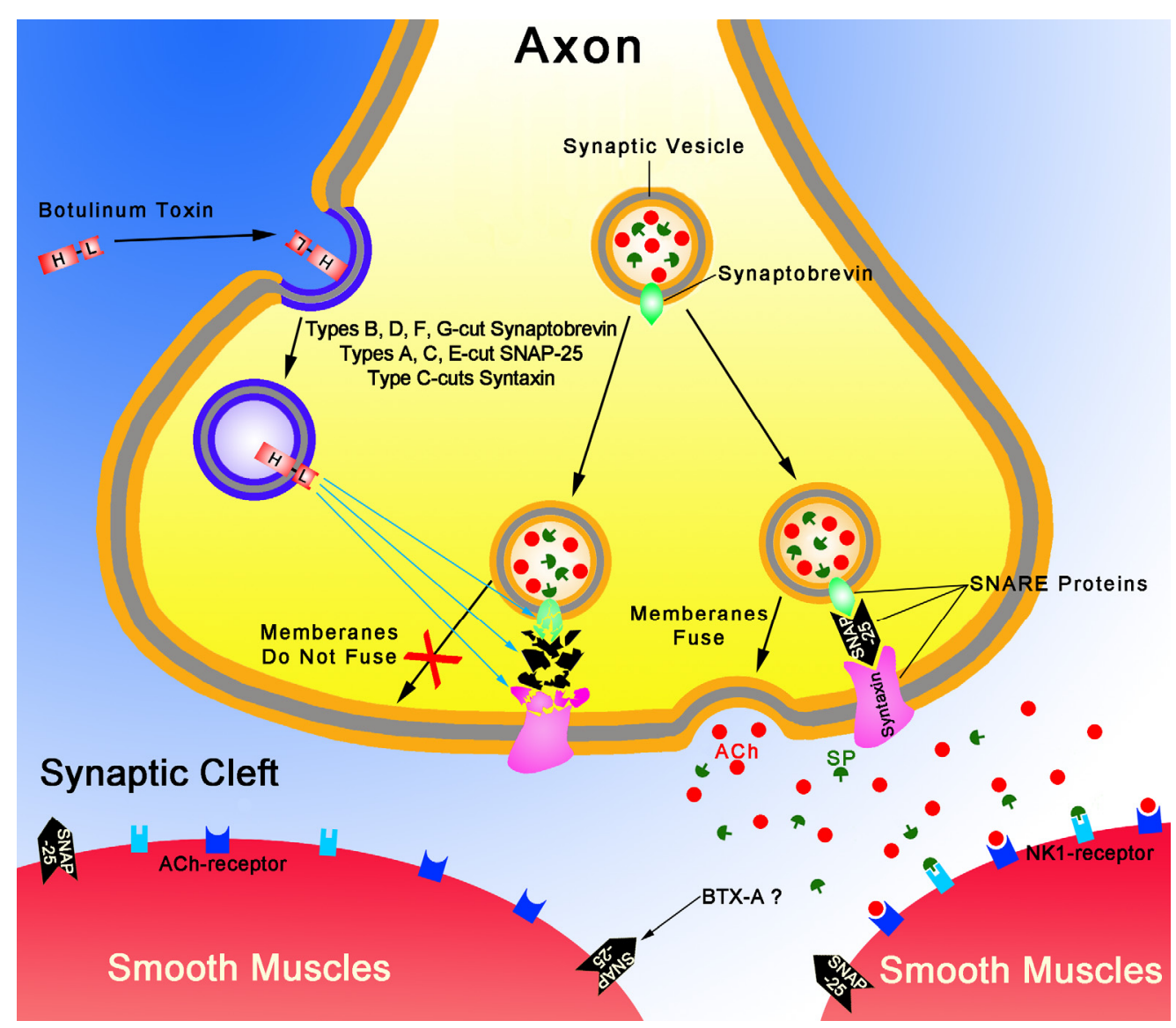

Figure 5. A presumed mechanism of inhibitory effect of BTX-A on smooth muscles is schematized. 
In summary, the evidence that SP- and NK1R-IR fibers and neurons located within mucosa and circular muscle layer of pylorus suggests that SP through NK1R innervates pyloric muscle for regulation of gastric emptying. BTX-A reduced the expression of SP-IR fibers in pylorus, and further inhibits EFS-induced contractile responses after atropine blocking muscarinic cholinergic receptors, and then NK1R antagonist administration does not act on EFS-induced contractile responses, suggesting inhibition of SP release from pyloric nervous terminals. BTX-A directly inhibits SP-induced pyloric smooth muscle contractility in a concentration- and time-dependent manner.

\section{Materials and Methods}

\subsection{Animals}

Adult Sprague-Dawley rats (Experimental Animal Center, Lanzhou University, Lanzhou, China) weighing 200-250 g were housed individually in cage with food and water ad libitum, kept on a 12-h light-dark cycle (light 07:00-19:00 h), room temperature at $21 \pm 1{ }^{\circ} \mathrm{C}$ and relative humidity at $50 \%$ for seven days before experiments. Experimental procedures were carried out in accordance with European Communities Council Directive of 24 November 1986 (86/609/EEC) and approved by the Institutional Animal Care and Use Committees of Gansu Province Medical Animal Center and Lanzhou University. All performances were undergone to minimize animal suffering and to use only the number of animals necessary to produce reliable scientific data.

\subsection{Pyloric Muscle Strip Preparation}

Before pyloric muscle strip preparation, animals were fasted for 18 to $24 \mathrm{~h}$, but water ad libitum. An approximately $10 \mathrm{~mm} \times 2 \mathrm{~mm}$ pyloric circular muscle strip was rapidly separated from per stomach after rat sacrificed by $\mathrm{CO}_{2}$ asphyxiation. The isolated strip was carefully rinsed and suspended by a string in an incubation bath containing $5 \mathrm{~mL}$ Krebs bicarbonate buffer solution composed (in mmol/L): $118 \mathrm{NaCl}, 4.7 \mathrm{KCl}, 2.5 \mathrm{CaCl}_{2}, 1.2 \mathrm{MgSO}_{4}, 24.9 \mathrm{NaHCO}_{3}, 1.2 \mathrm{NaH}_{2} \mathrm{PO}_{4}$ and 12.2 glucose, in which $\mathrm{pH}$ was adjusted to 7.4 , constant temperature was maintained at $37{ }^{\circ} \mathrm{C}$ and oxygenation was constantly bubbled with $95 \% \mathrm{O}_{2}-5 \% \mathrm{CO}_{2}$. One terminal of strip was attached to a muscular force transducer (JH-2, Space Medico-engineering Institute, Beijing, China) connected to a Mac Lab (model BL-420E, TM, Chengdu, China) for isometric tension recording. Two platinum electrodes placed adjacent and parallel to the long axis of the pyloric muscle strip, connected with electric stimulator (model Biolap $420 \mathrm{E}$ ) for setting EFS (parameter with $100 \mathrm{~V}, 4 \mathrm{~Hz}, 0.5 \mathrm{~ms}$ pulse width duration). Muscle strips were allowed to equilibrate for $60 \mathrm{~min}$ under a basal loading tension of $1 \mathrm{~g}$, and its spontaneous contractile waves were regularly emerged as its own control before EFS and adding drugs.

\subsection{Experimental Protocols}

In order to compare the inhibitory effect of BTX-A with antagonist of NK1R on pyloric muscle which contraction-induced by SP released from nervous terminals, after control response to EFS plus $100 \mu \mathrm{mol} / \mathrm{L}$ N $\omega$-nitro-L-arginine methyl ester (L-NAME, Sigma, St. Louis, MO, USA), an inhibitor of nitric oxide-mediated relaxation, for $30 \mathrm{~min}, 1 \mu \mathrm{mol} / \mathrm{L}$ atropine (Sigma, St. Louis, MO, USA), an antagonist of cholinergic muscarinic receptor, and $1 \mu \mathrm{mol} / \mathrm{L}$ APTL-SP (Sigma, St. Louis, MO, USA), 
an NK1R antagonist, were respectively added at intervals of $30 \mathrm{~min}$ in the first group of muscle strips ( $n=8$, Figure 1$)$. In the second group $(n=8)$, after control response to EFS + L-NAME, atropine, 10 U/mL BTX-A (GMP Nos. S10970037, 20061001, Lanzhou Institute of Biological Products, Lanzhou, China) and APTL-SP $(1 \mu \mathrm{mol} / \mathrm{L})$ were respectively added at intervals of $30 \mathrm{~min}$ (Figure 2).

To determine the inhibitory effect of BTX-A on SP-induced pyloric muscle contractions, after initial control response to SP ( $1 \mu \mathrm{mol} / \mathrm{L}$ Sigma, St. Louis, MO, USA) for $30 \mathrm{~min}$, incubational solutions were respectively replaced by Krebs + L-NAME $100 \mu \mathrm{mol} / \mathrm{L}+4$ or $10 \mathrm{U} / \mathrm{mL}$ BTX-A (each group $n=8)$ and continued for $4 \mathrm{~h}$. SP $(1 \mu \mathrm{mol} / \mathrm{L})$ was added at intervals of $30 \mathrm{~min}$ during the period (Figure 3$)$.

\subsection{Identification for the Distribution of SP and NK1R Cells and Fibers in Pylorus}

Under deep anesthesia with chloral hydrate (400 $\mathrm{mg} / \mathrm{kg}$ body mass, i.p.), five adult rats without BTX-A treatment as control were perfused through the ascending aorta with $100 \mathrm{~mL}$ of saline, followed by $350 \mathrm{~mL}$ of phosphate buffer ( $\mathrm{PB}, 0.1 \mathrm{~mol} / \mathrm{L}, \mathrm{pH} 7.4,4{ }^{\circ} \mathrm{C}$ ) containing $4 \%$ paraformaldehyde. After perfusion, pylorus was carefully dissected from stomach and post-fixed overnight in the same solution. Pyloric muscle strips from 5 adult rats treated with BTX-A were prepared as described before, and incubated into Krebs solution containing $10 \mathrm{U} / \mathrm{mL}$ BTX-A at $37{ }^{\circ} \mathrm{C}$ for four hours, then into the $4 \%$ paraformaldehyde to post-fixed overnight. All pylorus were rinsing for $48-72 \mathrm{~h}$ in PB containing $30 \%$ sucrose $\left(4^{\circ} \mathrm{C}\right)$, and sectioned $(30 \mu \mathrm{m})$ on a cryostat at $-25^{\circ} \mathrm{C}$. Some sections were performed with immunofluorescence procedure as described in our previous studies [16,49]. Briefly, adjacent sections were respectively incubated with rabbit anti-NK1R (Millipore, Temecula, CA, USA) or rabbit anti-SP (Millipore, Temecula, CA, USA) serum diluted 1:2000 in $0.01 \mathrm{M}$ PB saline containing $0.25 \%$ Triton $\mathrm{X}-100$ (PBS-T, $\mathrm{pH}$ 7.4) for $24 \mathrm{~h}$ on an agitator at $4{ }^{\circ} \mathrm{C}$. After rinses, the sections were placed in fluorescein isothiocyanate (FITC)-conjugated goat anti-rabbit IgG (1:500; Invitrogen, Carlsbad, CA, USA) for $2 \mathrm{~h}$ at $37^{\circ} \mathrm{C}$. Parallel control series were treated in the absence of the primary antibodies and in the presence of normal rabbit sera to assure the absence of any non-specific labeling with these procedures. Sections were mounted and then coverslipped with glycerol. Fluorescent immunostained cells and fibers were visualized by fluorescence microscope (Nikon, Tokyo, Japan). Other sections were mounted on gelatin-coated glass slides, stained with hematoxylin and eosin (HE) for histological assessing the distribution and morphology of SP and NK1R containing cells. Digital images were optimized for image resolution in Adobe Photoshop 12.0.

\subsection{Data Analysis}

Each preparation served as its own control with the tension and frequency of muscle stripe contractility in Krebs solution was compared respectively with the contractile response to EFS or drugs. The values were expressed as means \pm SEM. The data were statistically analyzed using one-way ANOVA followed by Fisher's PLSD test. Differences between means from experimental groups were considered significant at the $p<0.05$.

The morphological distributions of NK1R- and SP-IR cells and fibers in pyloric mucous and sphincter (Figure 4A) from all samples treated with or without BTX-A were analyzed using a $490 \mathrm{~nm}$ excitation filter and $520 \mathrm{~nm}$ emission filter under fluorescence microscope (Nikon). The NK1R- and SP-IR cells and fibers were determined according to Harrington et al. [50] and Lomax et al. [51], in which SP-IR 
fibers show a beaded fluorescence and distribute similar to enteric nervous plexus, and NK1R-IR cellular fluorescence locate within mucous and sphincter.

\section{Acknowledgments}

The work was supported by grants 090NKCA112 from Support Program of Gansu Provincial Science and Technology Department and KLPSGS0802 from Key Laboratory of Preclinical Study for New Drugs of Gansu Province, Lanzhou University.

\section{Author Contributions}

Yi-Ping Hou, Yu-Feng Shao, and Jun-Fan Xie conceived and designed the experiments; Yu-Feng Shao, Jun-Fan Xie, Yin-Xiang Ren, Can Wang and Xiao-Jian Zong performed the experiments; Yu-Feng Shao, Jun-Fan Xie and Yin-Xiang Ren analyzed the data; Lin-Lan Fan contributed reagents/materials analysis tools; Yi-Ping Hou, Yu-Feng Shao and Xiang-Pan Kong wrote the paper.

\section{Conflicts of Interest}

The authors declare no conflict of interest.

\section{References}

1. Simpson, L.L. Molecular pharmacology of botulinum toxin and tetanus toxin. Annu. Rev. Pharmacol. Toxicol. 1986, 26, 427-453.

2. Goonetilleke, A.; Harris, J.B. Clostridial neurotoxins. J. Neurol. Neurosurg. Psychiatry 2004, 75 (Suppl. 3), iii35-iii39.

3. Maslanka, S.E.; Luquez, C.; Dykes, J.K.; Tepp, W.H.; Pier, C.L.; Pellett, S.; Raphael, B.H.; Kalb, S.R.; Barr, J.R.; Rao, A.; et al. A novel botulinum neurotoxin, previously reported as serotype $\mathrm{h}$, has a hybrid-like structure with regions of similarity to the structures of serotypes a and $\mathrm{f}$ and is neutralized with serotype a antitoxin. J. Infect. Dis. 2015, doi:10.1093/infdis/jiv327.

4. Jankovic, J.; Brin, M.F. Therapeutic uses of botulinum toxin. N. Engl. J. Med. 1991, 324, 1186-1194.

5. Dressler, D.; Saberi, F.A.; Barbosa, E.R. Botulinum toxin: Mechanisms of action. Arq Neuropsiquiatr 2005, 63, 180-185.

6. Elston, J.S. Botulinum toxin therapy for involuntary facial movement. Eye (Lond. Engl.) 1988, 2, $12-15$.

7. Schantz, E.J.; Johnson, E.A. Properties and use of botulinum toxin and other microbial neurotoxins in medicine. Microbiol. Rev. 1992, 56, 80-99.

8. Lowe, N.J.; Lowe, P. Botulinum toxins for facial lines: A concise review. Dermatol. Ther. (Heidelb) 2012, $2,14$.

9. Huang, L.; Chen, H.X.; Ding, X.D.; Xiao, H.Q.; Wang, W.; Wang, H. Efficacy analysis of ultrasound-guided local injection of botulinum toxin type a treatment with orthopedic joint brace in patients with cervical dystonia. Eur. Rev. Med. Pharmacol. Sci. 2015, 19, 1989-1993. 
10. Ezzeddine, D.; Jit, R.; Katz, N.; Gopalswamy, N.; Bhutani, M.S. Pyloric injection of botulinum toxin for treatment of diabetic gastroparesis. Gastrointest. Endosc. 2002, 55, 920-923.

11. Lacy, B.E.; Zayat, E.N.; Crowell, M.D.; Schuster, M.M. Botulinum toxin for the treatment of gastroparesis: A preliminary report. Am. J. Gastroenterol. 2002, 97, 1548-1552.

12. Miller, L.S.; Szych, G.A.; Kantor, S.B.; Bromer, M.Q.; Knight, L.C.; Maurer, A.H.; Fisher, R.S.; Parkman, H.P. Treatment of idiopathic gastroparesis with injection of botulinum toxin into the pyloric sphincter muscle. Am. J. Gastroenterol. 2002, 97, 1653-1660.

13. MacKenzie, I.; Burnstock, G.; Dolly, J.O. The effects of purified botulinum neurotoxin type a on cholinergic, adrenergic and non-adrenergic, atropine-resistant autonomic neuromuscular transmission. Neuroscience 1982, 7, 997-1006.

14. James, A.N.; Ryan, J.P.; Parkman, H.P. Inhibitory effects of botulinum toxin on pyloric and antral smooth muscle. Am. J. Physiol. Gastrointest. Liver Physiol. 2003, 285, G291-G297.

15. Sand, J.; Nordback, I.; Arvola, P.; Porsti, I.; Kalloo, A.; Pasricha, P. Effects of botulinum toxin a on the sphincter of oddi: An in vivo and in vitro study. Gut 1998, 42, 507-510.

16. Hou, Y.P.; Zhang, Y.P.; Song, Y.F.; Zhu, C.M.; Wang, Y.C.; Xie, G.L. Botulinum toxin type a inhibits rat pyloric myoelectrical activity and substance p release in vivo. Can. J. Physiol. Pharmacol. 2007, 85, 209-214.

17. Huizinga, J.D.; Chang, G.; Diamant, N.E.; El-Sharkawy, T.Y. Electrophysiological basis of excitation of canine colonic circular muscle by cholinergic agents and substance p. J. Pharmacol. Exp. Ther. 1984, 231, 692-699.

18. Keef, K.D.; Ward, S.M.; Stevens, R.J.; Frey, B.W.; Sanders, K.M. Electrical and mechanical effects of acetylcholine and substance $\mathrm{p}$ in subregions of canine colon. Am. J. Physiol. 1992, 262, G298-G307.

19. Milenov, K.; Golenhofen, K. Differentiated contractile responses of gastric smooth muscle to substance p. Pflugers Arch. 1983, 397, 29-34.

20. Malone, E.D.; Kannan, M.S.; Brown, D.R.; Turner, T.A.; Trent, A.M. Adrenergic, cholinergic, and nonadrenergic-noncholinergic intrinsic innervation of the jejunum in horses. Am. J. Vet. Res. 1999, 60, 898-904.

21. Milenov, K.; Oehme, P.; Bienert, M.; Bergmann, J. Effect of substance p on mechanical and myoelectrical activities of stomach and small intestines in conscious dog. Arch. Int. Pharmacodyn. Ther. 1978, 233, 251-260.

22. Wen, W.D.; Yuan, F.; Wang, J.L.; Hou, Y.P. Botulinum toxin therapy in the ovalbumin-sensitized rat. Neuroimmunomodulation 2007, 14, 78-83.

23. Ishikawa, H.; Mitsui, Y.; Yoshitomi, T.; Mashimo, K.; Aoki, S.; Mukuno, K.; Shimizu, K. Presynaptic effects of botulinum toxin type a on the neuronally evoked response of albino and pigmented rabbit iris sphincter and dilator muscles. Jpn. J. Ophthalmol. 2000, 44, 106-109.

24. Welch, M.J.; Purkiss, J.R.; Foster, K.A. Sensitivity of embryonic rat dorsal root ganglia neurons to clostridium botulinum neurotoxins. Toxicon 2000, 38, 245-258.

25. Lucioni, A.; Bales, G.T.; Lotan, T.L.; McGehee, D.S.; Cook, S.P.; Rapp, D.E. Botulinum toxin type a inhibits sensory neuropeptide release in rat bladder models of acute injury and chronic inflammation. BJU Int. 2008, 101, 366-370. 
26. Marks, J.M.; Bower, A.L.; Goormastic, M.; Malycky, J.L.; Ponsky, J.L. A comparison of common bile duct pressures after botulinum toxin injection into the sphincter of oddi versus biliary stenting in a canine model. Am. J. Surg. 2001, 181, 60-64.

27. Bagheri, M.; Jahromi, B.M.; Bagheri, M.; Borhani Haghighi, A.; Noorafshan, A.; Kumar, P.V.; Omrani, G.R. A pilot study on lipolytic effect of subcutaneous botulinum toxin injection in rabbits. Anal. Quant. Cytol. Histol. 2010, 32, 186-191.

28. Domoto, T.; Yang, H.; Bishop, A.E.; Polak, J.M.; Oki, M. Distribution and origin of extrinsic nerve fibers containing calcitonin gene-related peptide, substance $\mathrm{p}$ and galanin in the rat upper rectum. Neurosci. Res. 1992, 15, 64-73.

29. Lindestrom, L.M.; Ekblad, E. Origins and projections of nerve fibres in rat pyloric sphincter. Auton. Neurosci. 2002, 97, 73-82.

30. Watanabe, Y.; Ohtsuka, T.; Kimura, H.; Matsunaga, T.; Tamura, K.; Ideno, N.; Aso, T.; Miyasaka, Y.; Ueda, J.; Takahata, S.; et al. Braun enteroenterostomy reduces delayed gastric emptying after pylorus-preserving pancreatoduodenectomy: A retrospective review. Am. J. Surg. 2015, 209, 369-377.

31. Rossetto, O.; Rigoni, M.; Montecucco, C. Different mechanism of blockade of neuroexocytosis by presynaptic neurotoxins. Toxicol. Lett. 2004, 149, 91-101.

32. Dolly, J.O. Molecular definition of neuronal targets for novel neurotherapeutics: Snares and kv1 channels. Neurotoxicology 2005, 26, 753-760.

33. Rao, K.N.; Kumaran, D.; Binz, T.; Swaminathan, S. Structural analysis of the catalytic domain of tetanus neurotoxin. Toxicon 2005, 45, 929-939.

34. Baskaran, P.; Lehmann, T.E.; Topchiy, E.; Thirunavukkarasu, N.; Cai, S.; Singh, B.R.; Deshpande, S.; Thyagarajan, B. Effects of enzymatically inactive recombinant botulinum neurotoxin type a at the mouse neuromuscular junctions. Toxicon 2013, 72, 71-80.

35. Ma, J.; Shen, J.; Lee, C.A.; Elsaidi, G.A.; Smith, T.L.; Walker, F.O.; Rushing, J.T.; Tan, K.H.; Koman, L.A.; Smith, B.P. Gene expression of nachr, snap-25 and gap-43 in skeletal muscles following botulinum toxin a injection: A study in rats. J. Orthop. Res. 2005, 23, 302-309.

36. Simpson, L.L.; Maksymowych, A.B.; Kouguchi, H.; Dubois, G.; Bora, R.S.; Joshi, S. The role of exoproteases in governing intraneuronal metabolism of botulinum toxin. Protein J. 2005, 24, $155-165$.

37. Blasi, J.; Chapman, E.R.; Link, E.; Binz, T.; Yamasaki, S.; De Camilli, P.; Sudhof, T.C.; Niemann, H.; Jahn, R. Botulinum neurotoxin a selectively cleaves the synaptic protein snap-25. Nature 1993, 365, $160-163$.

38. Washbourne, P.; Pellizzari, R.; Baldini, G.; Wilson, M.C.; Montecucco, C. Botulinum neurotoxin types a and e require the snare motif in snap-25 for proteolysis. FEBS Lett. 1997, 418, 1-5.

39. Eswaramoorthy, S.; Kumaran, D.; Swaminathan, S. A novel mechanism for clostridium botulinum neurotoxin inhibition. Biochemistry 2002, 41, 9795-9802.

40. Lawrence, G.W.; Foran, P.; Oliver Dolly, J. Insights into a basis for incomplete inhibition by botulinum toxin a of ca2+-evoked exocytosis from permeabilised chromaffin cells. Toxicology 2002, 181-182, 249-253.

41. Niel, J.P.; Bywater, R.A.; Taylor, G.S. Effect of substance p on non-cholinergic fast and slow post-stimulus depolarization in the guinea-pig ileum. J. Auton. Nerv Syst. 1983, 9, 573-584. 
42. Taylor, G.S.; Bywater, R.A. Antagonism of non-cholinergic excitatory junction potentials in the guinea-pig ileum by a substance p analogue antagonist. Neurosci. Lett. 1986, 63, 23-26.

43. Llewellyn-Smith, I.J.; Furness, J.B.; Gibbins, I.L.; Costa, M. Quantitative ultrastructural analysis of enkephalin-, substance p-, and vip-immunoreactive nerve fibers in the circular muscle of the guinea pig small intestine. J. Comp. Neurol. 1988, 272, 139-148.

44. Steele, P.A.; Brookes, S.J.; Costa, M. Immunohistochemical identification of cholinergic neurons in the myenteric plexus of guinea-pig small intestine. Neuroscience 1991, 45, 227-239.

45. Furness, J.B.; Pompolo, S.; Shuttleworth, C.W.; Burleigh, D.E. Light- and electron-microscopic immunochemical analysis of nerve fibre types innervating the taenia of the guinea-pig caecum. Cell Tissue Res. 1992, 270, 125-137.

46. Li, C.P.; Micci, M.A.; Murthy, K.S.; Pasricha, P.J. Substance P is essential for maintaining gut muscle contractility: A novel role for coneurotransmission revealed by botulinum toxin. Am. $J$. Physiol. Gastrointest. Liver Physiol. 2014, 306, G839-G848.

47. Ji, J.; Lau, H.; Sheu, L.; Diamant, N.E.; Gaisano, H.Y. Distinct regional expression of snare proteins in the feline oesophagus. Neurogastroenterol. Motil. 2002, 14, 383-394.

48. Ji, J.; Salapatek, A.M.; Lau, H.; Wang, G.; Gaisano, H.Y.; Diamant, N.E. Snap-25, a snare protein, inhibits two types of k channels in esophageal smooth muscle. Gastroenterology 2002, 122, 994-1006.

49. Hou, Y.P.; Manns, I.D.; Jones, B.E. Immunostaining of cholinergic pontomesencephalic neurons for alpha 1 versus alpha 2 adrenergic receptors suggests different sleep-wake state activities and roles. Neuroscience 2002, 114, 517-521.

50. Harrington, A.M.; Hutson, J.M.; Southwell, B.R. Immunohistochemical localization of substance P NK1 receptor in guinea distal colon. Neurogastroenterol. Motil. 2005, 17, 727-737.

51. Lomax, A.E.G.; Bertrand, P.P.; Furness, J.B. Identification of the populations of enteric neurons that have NK1 tachykinin receptors in the guinea-pig small intestine. Cell Tissue Res. 1998, 294, $27-33$.

(C) 2015 by the authors; licensee MDPI, Basel, Switzerland. This article is an open access article distributed under the terms and conditions of the Creative Commons Attribution license (http://creativecommons.org/licenses/by/4.0/). 